\title{
Lab-Grown Meat and Veganism: A Virtue-Oriented Perspective
}

\section{Carlo Alvaro ${ }^{1}$}

Accepted: 18 February 2019

(c) Springer Nature B.V. 2019

\begin{abstract}
The project of growing meat artificially represents for some the next best thing to humanity. If successful, it could be the solution to several problems, such as feeding a growing global population while reducing the environmental impact of raising animals for food and, of course, reducing the amount and degree of animal cruelty and suffering that is involved in animal farming. In this paper, I argue that the issue of the morality of such a project has been framed only in terms of the best consequences for the environment, animals, and humans, or in terms of deontic principles. I argue that to appreciate how deep and difficult this issue is, it is necessary to consider it in terms of a virtue-oriented approach. Such an approach will reveal aspects that are not apparent, not contemplated by typical approaches, but are essential to our understanding of the morality of lab-grown meat. As I argue, evaluating the issue from a virtue-oriented perspective suggests that the project of in vitro meat should not be supported because it stems from unvirtuous motivations.
\end{abstract}

Keywords Virtue ethics · In vitro meat · Lab-grown meat - Temperance · Wisdom of repugnance

As human ingenuity progresses, new moral questions present themselves. Nowadays, technology has come to the point where human and animal parts can be grown in a laboratory. As aptly described by an article in the Smithsonian Magazine (Vogel 2010) with the suggestive title, "Organs Made to Order", scientists are now able to build replacement body parts from the cells of a patient. And in August 2013, Professor Mark Post created the first in vitro burger at the University of Maastricht. Leaving aside the morality of growing human parts in a lab for medical use, our question is this: Is growing meat in a laboratory ethical and worth pursuing? This question is tremendously interesting especially to ethical vegans. An ethical vegan is one who avoids consuming animal food or using animal products. The

Carlo Alvaro

philonew@gmail.com

1 New York City College of Technology, City University of New York, Brooklyn, NY, USA

Published online: 26 February 2019 
typical argument for ethical veganism is that eating animal food and using products derived from the exploitation of animals is immoral because animals feel pain, and also because animal agriculture is one of the leading causes of environmental degradation.

There are many ethical vegans who avoid animal food because they do not like the taste of meat. However, there are also many who wish there was a way to eat it if meat were cruelty free and environmentally friendly. Lab-grown meat ${ }^{1}$ is purported to be the solution. In fact, if scientists can make it taste identical to "real" meat, animals will no longer be required, and consequently the impact on the environment will be reduced. Thus lab-grown meat seems to be like manna from heaven. What else do we need to know? If the question is, "Is growing meat in a lab a moral practice" it would seem that the answer is simple: Yes it is! Even those ethical vegans who like meat but abstain from eating it for ethical reasons could welcome and consume artificial meat (a very strange form of veganism, though). After all, isn't the prospect of eliminating animal suffering and saving the environment exactly what ethical vegans have been fighting for? It would seem that if meat is produced artificially reducing environmental damage, and no animal is disrespected or hurt, ethical vegans would have nothing more to complain about.

But it is not that simple. There are certain issues to be considered. For example, at present, animals still have to be used in the production of cultured meat. Whether painful or painless, animals must be reared so that their cells can be harvested to produce in vitro meat. Consequently, lab-grown meat still involves animal exploitation, which is what the proponents of artificially grown meat want to avoid. It might be the case that researchers or the FDA or any other entity argue that eating in vitro meat is risk-free. They could say that lab-grown meat is safe and non-carcinogen or in any way bad for human health. But how could they possibly know about longterm effects? My main concern is this: if it is meat, whether lab or factory grown, it is still meat, and thus unhealthful to humans. (Johns Hopkins Bloomberg School of Public Health, n.d., "Health \& Environmental Implications") Furthermore, it would seem that meat eaters, at least at present, do not like the idea of eating something made in a laboratory. Granted, it is possible that in the future they will overcome their squeamishness. However, it is reasonable to believe that not all meat eaters will. Thus, lab-grown meat may never completely replace traditional animal farming, but rather be just another option: "Which steak, sir? Lab-grown or farmgrown?" Consequently, growing synthetic meat might just make little to no difference to the current state of animals being raised for food.

But assume that in the future lab-grown meat will become readily available, cruelty-free, affordable, environmentally safe, and taste the same as real meat, (call this the "desirable outcome thesis") what would then be the moral problem? In my view, what could still be said against lab-grown meat is to point out its unvirtuous motivation. Namely, why are we humans even contemplating eating food that is produced synthetically in laboratories, given the abundance of naturally grown plant-based

\footnotetext{
${ }^{1}$ I will henceforth use interchangeably the terms 'lab-grown meat', 'in vitro meat', 'artificial meat', synthesized meat, and 'cultured meat'.
} 
food? By framing the question of lab-grown meat in terms of virtue, creating meat in a laboratory just seems obstinate and evinces lack of temperance and a misunderstanding of the role of food in human flourishing. Are we supposed, as humanity, to place so much importance to food that we are willing to create it in laboratories? A virtue-based approach can make sense of this issue in a way that other theories cannot, because it does not stop at the consideration of what is most convenient or what is our duty. A virtue-based approach considers the motivation and character of individuals. What are the virtues and how can they help? Particularly the virtue of temperance can make us see what is wrong with cultured meat. If we judge from the perspective of temperance, we realize that the issue of cloned meat is not merely whether or not such meat is cruelty-free or it tastes like real meat.

In a well-known paper, Anscombe (1958) pointed out that we should drop the idea of obligation altogether. And that is what we need to do if we wish to understand the morality of lab-grown meat. The current discussion is focused on the rightness or wrongness of such an endeavor. But all along there is an important question, the question of character, which is being marginalized by the practicality of achieving viable lab-grown meat. Virtue ethics has the advantage of making sense of this issue by shifting the focus of the discussion over the character of the individual. It shows that the best approach to eating is one according to virtue. The pertinent virtue is temperance because, as Aristotle pointed out, temperance has to do with physical appetites, or brutish, as he put it in the Ethics. A temperate individual is one whose approach to eating is measured by reason. The temperate individual eats food that is conducive to health, and eats in moderation, "as long as they are not incompatible with health or vigor, contrary with what is noble, or beyond his means". Temperate individuals are not attracted to foods merely for the smell or taste or pleasure. Rather, they eat in moderation, not to satisfy pleasure, but to be nourished. Temperate individuals always choose those foods that are healthful. (Aristotle 2002, Book III, 10-12).

What is important to consider is that my argument focuses on the current state of affairs in affluent societies, where food is readily available and abundant. My argument relies on current scientific data showing that plant-based diets are optimal at any stage of life. (Craig and Mangels 2009) According to the American Dietetic Association "appropriately planned vegetarian diets, including total vegetarian or vegan diets, are healthful, nutritionally adequate, and may provide health benefits in the prevention and treatment of certain diseases." (Tuso et al. 2013, p. 61), Thus, animal food is not necessary for good health. In fact, the contrary is true; the current scientific literature constantly reminds us that consuming animal food is always associated with many health problems, such as heart disease, diabetes, obesity, atherosclerosis formation, cancer, and more. (Bouvard et al. 2015) I anticipate resistance here. Many people believe that although scientific research speaks negatively about animal food, it does not mean that we need to abandon it altogether. It is all too often said that there is such a thing as eating in moderation. In fact, in an earlier version of this paper, a referee made the following comment: "The fact that a diet rich in beef correlates with increased risk of heart disease does not mean that, for health reasons, one should avoid eating any beef at all, let alone all meats including fish." 
The first point that I want to make is that, to be correct, the scientific research on animal food consumption's effects on human health doesn't show that beef correlates just with increased risk of heart disease; rather, it shows an increased risk of heart disease, cancer, diabetes, high blood pressure, and cognitive decline, among many other issues. Secondly, the research clearly shows that beef is not the only culprit. For example, a recent study, with the self-explanatory title, "Fish Intake Is Positively Associated with Breast Cancer Incidence Rate" concludes that, "higher intakes of fish were significantly associated with higher incidence rates of breast cancer." (Stripp et al. 2003, p. 3664) Although red meats are the most dangerous, all meats, including farm-raised fish, as well as other animal products, correlate with increased risk of health problems. Not surprisingly, entities such as The American Institute for Cancer Research, for example, recommends reducing consumption of red meats, having meat-less days, and avoiding processed meats completely. And the last point: if the fact that consuming meat correlates with increased risk of many diseases does not mean that meat should be avoided, I wonder what does. Obviously, in the end people are free to choose their diet. But if science consistently shows that animal food is known to cause many health problems, the sensible thing to do is to avoid animal food. Why eat a food that has the potential to cause health problems in the first place. If something is potentially dangerous, the notion of moderation just does not apply.

Thus the conclusion that a temperate person avoids animal food, lab-grown or otherwise, follows from the following premises: (1) Animal food has been shown to cause a plethora of health problems. (2) It seems to be the sensible thing to do to avoid even in moderation a food that is dangerous for our health. For example, smoking a pack of cigarettes once per month or once a year may not be as deadly as, say, smoking two packs a day. But it seems (to me at least) sensible not to smoke at all to avoid health problems. (3) Fresh fruit and vegetables are never dangerous for our health, even when consumed in abundance. (4) A diet completely devoid of animal food is optimal - in fact desirable — at any stage of life and can prevent the aforementioned diseases. (5) Animal food has a deleterious impact upon the environment. (Of course, this premise, would not apply to in vitro meat under the assumption of the desirable outcome thesis.) (6) Alienation from nature is not conducive to flourishing, and producing lab-grown meat alienates us from nature. And (7) Giving up animal food when we have an abundance of readily available plant food is not a sacrifice of taste or nutrition since plant food is quite exquisite, nutritious, and abundant. Here I am not arguing that taste is irrelevant. One has to weigh taste against other factors, factors that in my view are obviously more important. We have to consider that taste can be easily adjusted, and that the taste of meat is not superior to the taste of plant-based food.

Consequently, the temperate individual will consume food that is essential to flourishing, and not primarily for its taste. From the point of view of temperance, since meat is not required for good health - in fact, it should be avoided whenever possible-eating meat whether lab-grown or farm-grown, should be avoided and not ethically supported. As I hope it will emerge from my discussion, the idea of growing meat in laboratories evinces lack of temperance; thus, in this sense I believe that ethical vegans should regard the prospect of lab-grown meat as an expression of 
intemperance, even under the assumption of the desirable outcome thesis. In what follows, I will discuss some of the negative aspects of the issue and later explore the possibility that considering lab-grown meat is a moral mistake that we might be able to see by embracing a virtue-oriented ethics.

The project of in vitro meat is typically addressed within the moral framework of consequentialist and deontic ethics (or some variations of these two). Considered from a consequentialist standpoint, the question of the morality of lab-grown meat would seem quite clear-cut. According to consequentialist ethics, an action is right just if its consequences lead to the promotion of maximum utility. Assuming the desirable outcome thesis, a consequentialist would certainly approve in vitro meat. Under this assumption, animal suffering would be dramatically reduced or perhaps even eliminated while meat eaters would have their fix and be happy. This scenario seems to be ideal from a utilitarian point of view. And in such a case, it would be the end of the story. Rights theorists or deontologists would differ in their approach from utilitarians, in the sense that the goal of deontology is to do the right thing for the right reason. But it would seem that even deontologists would have no problem supporting production of lab-meat. What I suggest, however, is that the story does not end here if we consider it from the standpoint of a virtue-based approach.

Before I consider my approach, I want to briefly discuss certain difficulties regarding the desirable outcome thesis. One issue is that to be really cruelty-free, it might be suggested, it should be animal-free. The challenge at present is for scientists to find a method of self-renewing stem cells and animal-free materials to accomplish the growth of synthetic meat. Very roughly explained, cells are taken from a living animal and allowed to grow in a Petri dish in a laboratory. In practical terms, the initial harvested cells are taken from animals that are raised according to specification so that their flesh can be genetically replicated in a lab. But is that the end of the process? Are animals off the hook after that (pun intended)? Dr. Post points out that, "the most efficient way of taking the process forward would still involve slaughter, [using a] limited herd of donor animals." (Collins 2012, 19 Feb 2019, para. 10) Granted, the number of animals involved could be reduced. It will not, however, dispense altogether with the use of animals. Scientists are working to create synthesized meat from an initial biopsy and get it going without resorting to further harvesting. If that were the case, (and of course at this point it is just speculation) one worry is that meat eaters might see that the sky is the limit when it comes to variety and taste. I want to be very careful here not to suggest something that might be understood as a fallacious slippery-slope; but at that point, if growing meat becomes as easy as researchers hope it to be, why not clone any kind of animal meat, including, but not limited to, wild animals. And what would be a moral objection to lab-grown human meat? Obviously it would be a lab product, but nevertheless could taste like human flesh and could be marketed as such. Certainly some might argue that as long as people are not exploited or hurt in the process, squeamishness aside, there is nothing wrong with lab-grown human meat. But is this the direction that we are willing to take in order to satisfy our culinary extravagance? It is possible that lab meat producers would start harvesting cells from all kinds of animals (including human animals) and breeding or even cross-breeding exotic animals, which would take us right back to square one and, once again, require breeding animals for food. 
If scientists could overcome these difficulties, shouldn't vegans and animal rights activists accept in vitro meat as a morally viable project? I think that the answer to this, and similar questions, is predicated upon the kind of idea one assumes about morality. It depends on the moral outlook from which the issue of cultured meat is considered. As Anscombe (1958) pointed out in her frequently cited article, "Modern Moral Philosophy," ethics is typically done by assuming the notion of obligation or moral ought. She writes, "It would be a great improvement if, instead of 'morally wrong,' one always named a genus such as 'untruthful,' 'unchaste,' 'unjust'.' (p. 89) The important message of Anscombe and many other like-minded philosophers is that moral problems require the kind of attention to human character that a virtuebased theory can offer. It seems to me that the question of the morality of producing and consuming cultured meat is typically dealt with by a consideration of our duty or consideration of rights. Robert Louden (1984), referring to Anscombe's remark, writes, "But are we to take the assertion literally, and actually attempt to do moral theory without any concept of duty?" (p. 228) As far as I understand Anscombe, I do not think that she meant that we should do away with duty altogether. Perhaps I am wrong about what Anscombe really meant, but I am not suggesting here that duty is an unimportant aspect in morality. Rather, I want to suggest that in many cases trying to figure out our duty leads us nowhere. In the present issue, what is our duty? Ought we not to preserve the environment? Ought we not to avoid injustice and gratuitous suffering? The answer seems obviously "yes." And if lab-grown meat is capable of achieving such goals, then we have a duty to support lab-grown meat; consequently, according to duty ethics, that's the end of the story. But I think that a virtue-oriented approach is the correct framework to make sense of this issue because it enables us to see aspects of moral issues that are simply discounted by the duty or the maximum happiness approaches.

To see why the question of whether lab-grown meat is morally viable requires the attention of virtue ethics, I want to discuss the famous article "Virtue Theory and Abortion" by Rosalind Hursthouse, in which she discusses the morality of abortion in a way that parallels my argument here; that "abortion is commonly discussed in relation to just two considerations: first ...the status of the fetus...; secondly ... women's rights... Virtue theory quite transforms the discussion of abortion by dismissing the two familiar dominating considerations as, in a way, fundamentally irrelevant." (Hursthouse 1991, p. 233) And it seems to me that the question of the morality of cultured meat is often approached in relation to our duty or to the best consequences. No reference is ever made to virtue and character. Hursthouse's argument is that considering an issue such as abortion in the light of rights or duty is not helpful at all. In the case of abortion, questions of the status of the fetus and of women's rights are two of the most complicated questions in morality. The status of the fetus is a very controversial issue that may never be settled. And how far should the rights of women go is not a straightforward issue either. Virtue ethics focuses on whether or not our actions are in accordance with certain admirable character traits. Because every situation is different, it is often very hard to be able to figure out what our duty is. A woman's pregnancy could be the result of an accident, of rape, or of love. Consequently, whether abortion is right or not depends on the nature of that specific case. 
Hursthouse points out that her analysis of the morality of abortion is distinct from a question about whether women "have a moral right to terminate their pregnancies" precisely because "in exercising a moral right I can do something cruel, or callous, or selfish, light-minded, self-righteous, stupid, inconsiderate, disloyal, dishonest-that is, act viciously." (p. 235) Reasonable judgment, Hursthouse notes, ought to be made on the basis of "familiar biological facts," which are "the facts that most human societies are and have been familiar with...", namely, "standardly (but not invariably), pregnancy occurs as the result of sexual intercourse, that it lasts about 9 months, during which time the fetus grows and develops, that standardly it terminates in the birth of a living baby, and that this is how we all come to be" (p. 236).

Considering these facts, Hursthouse suggests, the question should be, "How do these familiar biological facts figure in the practical reasoning, actions and passions, thoughts and reactions, of the virtuous and the non-virtuous? What is the mark to having the right attitude to these facts and what manifests having the wrong attitude to them?" (p. 237) Her starting point is to note that abortion is a serious matter because it concerns "in some sense, the cutting off of a new human life." To dismiss it forthright reflects a fundamental misunderstanding of what is at stake. Accordingly, "to think of abortion as nothing but the killing of something that does not matter, or as nothing but the exercise of some right...or as the incidental means to some desirable state of affairs, is to do something callous and light-minded, the sort of thing that no virtuous and wise person would do." (p. 237-238) Deontological and utilitarian approaches, Hursthouse points out, are inadequate to appreciating the seriousness of life and of what is at stake in abortion.

It is necessary to take into account and weigh certain goods, such as the value of the human life that is cut off with abortion, the value of motherhood/parenthood for a woman, and the contribution of these factors to living a good, noble human life. Therefore, in order to be valid, a choice for abortion in a particular case must be granted by a desire to obtain or preserve goods that are superior to those goods that abortion cuts off.

The central issue in evaluating whether or not abortion is permissible is essentially a question of whether or not a woman exhibits a virtuous or vicious character; whether or not a woman understands the nature of the real goods that abortion generally cuts off. If one is knowingly sacrificing these goods in order to follow "other worthwhile pursuits" conducive to flourishing, which are incompatible with having a child, or because a pregnancy would place excessive burdens on her (especially in light of health issues of a woman) she is not thereby manifesting a vicious character, and therefore her choice of abortion may be justified.

So, what can be learned from Hursthouse's discussion of the morality of abortion that is valuable to the question of the morality of cultured meat? I believe that when we approach the desirable outcome thesis with a similar attitude as that proposed by Hursthouse toward abortion, we are immediately prompted to view the issue of cultured meat from a completely new angle; and we may realize that this new view features important issues that we have not yet contemplated. Approaching in vitro meat from a virtue-based perspective means weighing the goods that in vitro meat can generate against those goods that it cuts off. While in vitro meat could generate some goods in the way of reduced suffering and environmental benefit, the goods 
that it cuts off are too important to support in vitro meat. In my view, in vitro meat leads to our alienation from nature through dependence on technology, and perpetrates an attitude toward animals that sees them as means to our end-and that end is taste.

Considering that meat is not a requirement for good health, in fact, quite to the contrary, science shows that animal products can be harmful to human health, and considering that taste can easily be adjusted to plant food, rather than proposing meat grown in a lab, our efforts as a civilization should be pursuing ways to move toward a plant-based diet. Is it possible that we have made such a mess of things in the world by first bringing into existence millions of animals for food resulting in the possibly irreversible degradation of the environment and of our health that we now are contemplating eating lab-made food? It seems to me that cloning meat is just another step toward our alienation from nature. As Bhat et al. (2014) point out,

Another problem with the in vitro meat production system is that it may alienate us from nature and animals and can be a step in our retreat from nature to live in cities. Cultured meat fits in with an increasing dependence on technology, and the worry is that this comes with an ever greater estrangement from nature. In the absence of livestock based farming, fewer areas of land will be affected by human activities which is good for nature but it may at the same time alienate us from nature. (p. 9)

I think we can and should do better than that. I believe that the enthusiasm about lab-grown meat is mostly due to self-indulgence as well as shortsightedness. We should ask ourselves whether the mere taste of a food is so important that we are willing to produce it in a laboratory rather than adjusting our taste to plant food.

What I am referring to above involves the virtue of temperance, or lack thereof. The virtue of temperance can be understood, as Aristotle noted, by its connection with animality. For Aristotle, human beings are animals endowed with reason. As animals, they are naturally subject to appetites for food, drink, sex, and more. They are sensitive to the pleasures that the satisfaction of such appetites can bring. Since our animality is not the distinguishing aspect of our humanity, physical pleasures should not be of major importance to us. However, humans are susceptible to these pleasures because our animality is part of our essence. In other words, insofar as we are part animals and part rational beings, we have to deal with all kinds of physical pleasures in a way that harmonize with reason.

Temperate people relate properly to their animality, and give the proper worth to animalistic pleasures. Insensible, self-indulgent, or intemperate individuals, in their respective way, misjudge the importance of certain pleasures and misjudge themselves. Intemperate people place too much importance to the pleasures of food and drink. Invitro meat, it seems to me, is a perfect example of self-indulgence. We are supposed to eat and drink, primarily, because we require nourishment. Thanks to the ease of modern civilization, people who live in affluent societies, in my view, have lost sight of this fact and have placed too much importance to food. Food nowadays, for those of us who live comfortably, is more than fuel for the body. Here I do not at all intend to downplay the role of "taste" in a flourishing human life. I emphasized that we are supposed to eat and drink primarily because we require nourishment. 
But I want people to really enjoy the flavor (taste and olfaction) of the foods they eat-but food that comes at no cost to our health and to the environment. And I would say that temperance lies more in eating the right types of food in the right quantities. My point here is, however, how important is to satisfy our taste for meat that we are willing to create and consume lab-grown food? How should a virtuous person approach this situation? What behavior is consistent with temperance? I am not contemplating philosophical hypotheticals here. I am speaking practically: plantbased food is very delicious and nutritious, healthful, abundant, safe for us, and sustainable for the environment. Moreover, animal food is not safe; and while the taste of meat may be incredibly satisfying to many, it does not seem to me that, compared with plant-based food, meat is so sublime that life without it would not be worth living. The increasing number of people who become vegans and live happily is testimony that the taste of meat is not very important. Thus, these considerations represent good reasons to show that the temperate individual would reject the desirable outcome thesis of in vitro meat; and that in vitro meat is motivated by intemperance.

Food is necessary and pleasurable. But humans can (and indeed do) have the wrong desire for it. Generally, in affluent societies the wrong desire for food is manifested by the extravagance and excess of food that people eat. According to the Office of Disease Prevention and Health Promotion's dietary guidelines 2015-2020, "The typical eating patterns currently consumed by many in the United States do not align with the Dietary Guidelines." ("Current Eating Patterns", 2015, para. 1) To say that eating patterns in the US "do not align with the dietary guidelines" is a very mild way to put it when we consider that, "About three-fourths of the population" consumes a low amount of fruit and vegetables. Also, "More than half of the population is meeting or exceeding total grain and total protein foods recommendations, [and] are not meeting the recommendations for the subgroups within each of these food groups." In particular, "most Americans exceed the recommendations for added sugars, and saturated fats." (Para. 1) And saturated fats come mainly from animal sources, including meat and dairy products. Furthermore, "the eating patterns of many are too high in calories... The high percentage of the population that is overweight or obese suggests that many in the United States overconsume calories... more than two-thirds of all adults and nearly one-third of all children and youth in the United States are either overweight or obese." (Para. 1) These facts in my view clearly show that something about our relationship with food has gone completely wrong. These facts are not surprising considering that the idea of food, for many reasons and by many factors, has been distorted.

It seems clear that it is the lack of temperance that makes humans indulge in the wrong food and in the wrong way. Furthermore, self-indulgence leads to pain, more than it is required, when certain foods are missed. The self-indulgent value food too highly, choosing it at the cost of health. Thus, in relation to the bodily pleasure of food, one can be self-indulgent, weak-willed, self-controlled, temperate, or insensible. The temperate person will choose what is pleasant and conducive to health, which is in its turn conducive to flourishing. Consequently, since strong desires for food can easily lead us to destroying our health, the temperate person desires simple food and in moderation. When we survey the health sciences, it is clear that the only foods that can lower and prevent many health problems are fruits and vegetables. 
(Harvard T.H. Chan. School of Public Health, "Vegetables and Fruits" 2019) In fact, as far as I have researched, I have never seen any study, or heard any medical professional, recommend eating fruit and vegetables with caution while enjoying animal products.

Synthesizing meat also opens the door to the variety of meat that can be produced. It seems plausible that if laboratories crack the code and succeed in creating perfect replicas of meats, the next step would very likely be replicating the flesh of endangered species, wild animals, and alas, humans. Cannibalism is not a desirable practice in modern society and not only because the very idea of it is repulsive, but also because it can cause a disease known as Kuru (Gajdusek and Zigas 1957). But what if human flesh could be replicated without the risk of any disease? Although human flesh might be unlikely to become a popular dish, given the curiosity of human beings, there is still the prospect of cloning it for human consumption. This may sound like a slippery slope objection to lab-grown meat, but I don't think that it is in this case. I do not intend to pursue this as the main argument against lab-grown meat, however, but rather use the discussion to illustrate the kind of irrational path to which cloning meat leads.

But what exactly is the problem with cannibalism? Schaefer and Savulescu (2014) point out that,

The most obvious reaction to this possibility of human [in vitro meat] is to ban it. Just as, for instance, cloning is banned in the 13 US states and the European Union for moral reasons, we could put in place strict restrictions on the synthesis of human flesh for the purpose of consumption. Given common revulsion at the prospect of cannibalism, this reaction is indeed rather likely. However, it is too quick-we should ask first, what is so wrong with cannibalism of artificially created human cells and tissue that it must be banned? (p. 197)

Here they point out that despite our gut-feeling sense that cannibalism is wrong, in the end there is no good argument against eating human flesh as it merely amounts to feeling of disgust. In fact, cannibalism is morally objectionable because it (typically but not always) involves killing a person, and the desecration of a corpse. But if human flesh is cloned in a laboratory, then there is no killing or desecration involved. To produce in vitro human flesh for human consumption it would be required harvesting cells from people who are willing to donate their cells. In fact, this process may even become lucrative for many people who might be paid for their cells. At that point then, what would be wrong with eating human flesh?

Could it be disrespect toward humanity? Since there are no human beings required in the production of a hypothetical in vitro human flesh, no disrespect could be done. Schaefer and Savulescu thus conclude that if we are worried about in vitro meat because of cannibalism, we should not worry at all because such meat will be free of cruelty and disrespect-end of the story. Therefore, the objections that are typically raised against lab-grown meat rely on violation of respect and disgust, but they are not strong enough to reject the project of cloning meat for human consumption. Fewer animals being slaughtered, less animal suffering, less pollution, among many other factors, in their view, are powerful enough arguments showing that we should support research into cultured meat. 
As I already pointed out at the outset, it seems that there is a prevailing view about the moral viability of producing lab-grown meat that hinges on broadly consequentialist and deontic principles. Virtue ethics is not necessarily against the best consequences or the notion of rights. However, those should not be the only aspects that matter. As we have seen in the discussion of Hursthouse's view on abortion, sometimes in the name of the best consequences or in the name of our rights, we might act in ways that are callous, self-indulgent, selfish, and so on. Thus, it would certainly be an admirable prospect to reduce suffering and care for the environment. But is cloning meat the right way to accomplish those goals? I would like to suggest what a virtue-oriented approach could add to the discussion, and in so doing I will address cannibalism in particular, though the larger scope is to address in vitro meat. What I would like to suggest is something along the lines of what Leon Kass refers to as "the wisdom of repugnance", which is the same concept that Mary Midgley and others call the "yuck factor." This is the notion that a strong, negative reaction of disgust to a practice is in fact good enough evidence that such a practice is not morally sound or that there is something intrinsically wrong with it. In "Danger to Human Dignity: the Revival of Disgust and Shame in the Law" Nussbaum (2004) points out that the "yuck factor" or disgust has been used in many arguments throughout history as a justification for evil practices and institutions, such as slavery, torture, antisemitism, gender and sexual discrimination, and so on. But it seems to me, and many others, that just because feeling of disgust may lead to the wrong conclusion, it does not follow that this feeling should be discounted forthright. There are cases and cases. Our feeling of revulsion may not be in itself an argument against a practice, but it certainly signals that something requires our attention because it might be morally wrong. Surely we can in many cases supply reason to this feeling and construct an argument. But even in the case that a fully articulated argument is not forthcoming, I do not think that in certain cases one is not entitled to reject a practice, like in this case in vitro meat, on the basis of disgust. In fact, Kass (1997) seems to think so, as he argues the following about the feeling of revulsion,

Revulsion is not an argument; and some of yesterday's repugnances are today calmly accepted - though, one must add, not always for the better. In crucial cases, however, repugnance is the emotional expression of deep wisdom, beyond reason's power fully to articulate it. Can anyone really give an argument fully adequate to the horror which is father-daughter incest (even with consent), or having sex with animals, or mutilating a corpse, or eating human flesh, or even just (just!) raping or murdering another human being? Would anybody's failure to give full rational justification for his or her revulsion at these practices make that revulsion ethically suspect? Not at all. On the contrary, we are suspicious of those who think that they can rationalize away our horror, say, by trying to explain the enormity of incest with arguments only about the genetic risks of inbreeding. (p. 20)

The natural feeling of repugnance at cannibalism, and in general at lab-grown meat, belongs in this category. We are repelled by the prospect of cannibalism and cloned meat because we feel directly that such a practice violates our moral virtues by overemphasizing the importance of taste and by ultimately alienating us from 
nature. What kind of person am I to support artificial meat when it is possible-in fact it is preferable-to thrive eating plants and fruit? Is the taste of meat so important that we are willing to allow technology to take over our lives to the point of manufacturing flesh? These are some of the questions that are part of that feeling of disgust. Repugnance, thus, is a natural reaction against the excesses of human willfulness to distance itself from nature. In this case, I believe, the repugnance expressed at the prospect of producing meat artificially is justified. Conversely, in the cases of sexism, racism, slavery, and other forms of discrimination, our feeling of repugnance is not justified because it stems from contempt, anger, and selfdelusion. But, in the case of cultured meat, repugnance is the cry out of our human nature that is being overtaken and changed by technology, the blind hunger for innovation, profit, and self-indulgence.

So why is repugnance at lab-grown meat a morally legitimate reaction? To answer this question, I would go back to what I have been describing throughout this paper. It is true that as Nussbaum states repugnance has been used in history to justify evil things. Granted, but firstly it is quite clear that the case of repugnance at in vitro meat does not involve any form of evil or discrimination. Secondly, the sense of repugnance that I refer to in the case of lab-grown meat is not unfounded; after all, it is corroborated by those factors previously discussed: the fear of alienation from nature, and the fear that the quest for technological advance rather than careful moral consideration is corrupting our moral character, our temperance, to the point of overestimating the importance of taste. Indeed, taste is important, but not so much that we are willing to create laboratory food when we have access to readily available, nutritious, exquisite, healthful, suffering-free, and sustainable plant food. These are good reasons why we are repelled by cannibalism and in vitro meat. That is, such practices stem from the legitimate fear of estrangement from our nature in the way of becoming dependent on lab-grown food. We should not allow technology to modify our nature such that we start eating lab-grown food. We should not, if we worry about our moral character, if we are temperate, sensible, and compassionate, allow technology to turn the world into a place where all kinds of meat-including human meat-are produced in a laboratory. Are these practices conducive to our flourishing? Is the taste of meat so important that we are willing to come to this? I think not. In my view the temperate and most practical approach is to harmonize with nature, not exploit animals, and consume plant-based food.

As a concluding remark, I would like to point out that my discussion about the morality of producing and eating lab-grown meat is supposed to illustrate what a virtue-oriented theory can add to the discussion. Moreover, it is a view that the ethical vegan might take with respect to the morality of in vitro meat. Ethical veganism, as I understand it, is the rejection of animal-based products as food, whether these products come from living animals or a lab. Ethical veganism should be based on virtue rather than deontic or consequentialist principles. Ethical veganism should be the embodiment of virtue and thus should reject the notion of using animals for our taste and pleasure because doing so evinces lack of temperance, compassion, fairness, and magnanimity. (Alvaro 2017a, 2019) Consequently, an ethical vegan should not support the production of any kind of meat. However, not all vegans think this way. For example, Ingrid Newkirk, founder 
and president of People for the Ethical Treatment of Animals (PETA), offered \$1 million to successful production of lab-grown meat. (Phillips 2009, para. 2) As an ethical vegan, this seems to me a peculiar and sad form of veganism. In my view, the reason for this schism among vegans is due to the fact that the question of the morality of lab-grown meat has been framed typically in terms of potential future gains, which seems to me to be an approach of consequentialist nature; or another typical approach is of deontic nature. These approaches seek to rationalize the question of lab-grown meat, and certainly in their way they seem to achieve the goal of demonstrating that cloning meat for human consumption is morally viable and makes a lot of sense to support the project. After all, aren't less pollution and fewer animals suffering what we all want?

Yes, but as I hope to have shown, while those are important factors, they are not the only factors to be considered. Focusing only on those factors may lead to a tunnel-vision-like understanding of the issue. The contribution of a virtue-oriented approach is to show that, for example, the way we are going about reducing suffering and environmental degradation seems to completely disregard the importance of having an admirable character. In particular, the obstinate attitude of wanting meat at all costs by producing it in laboratories evinces a profound lack of temperance. Hocquette (2016) aptly concludes, "the global scientific community including the proponents of artificial meat themselves recognize the hurdles to overcome so that artificial meat can progress to the industrial stage (new formulation of culture media, development of giant incubators, safety assessment for human consumption, etc.). (p. 8) Also he notes that there are other alternatives to cultured meat "faster to develop in the short term and more effective in responding to today's issues (in particular it is the case of the reduction of waste) compared to artificial meat which still needs a great deal of research." (p. 9) A viable solution is, of course, that of plantbased meat substitutes, though in my view it would be more sustainable in the long run if we take steps toward abandoning what I regard as a primitive idea of animals as human food.

In light of the difficulties involved in the research for the production of viable in vitro meat, the virtue-oriented approach that I suggest is to ask the following questions: Is the taste of meat so important for humans that we are willing to alienate ourselves from nature more and more by producing food in laboratories? Is meat so important that we are willing to continue what Melanie Joy (2001) refers to as the culture of carnism? (p. 126-127) Is it necessary that we produce synthetic meat to "save" the environment and reduce animal cruelty and suffering when it would be much easier to adopt plant-based diets? My answer to these questions, of course, is no. Critics may, naturally, object to many of the points I made; but the overall point of my discussion has been that virtue theory has the resources to show why we should not support in vitro meat; also, my aim was to show that moral issues are better understood when framed in terms of virtue and vice rather than in terms of best consequences or of rights. The question of the morality of in vitro meat is typically addressed from the point of view of what is practical or what is our obligation. As I hope to have shown, approaching the question from a virtue-based perspective reveals to us an aspect of the issue that is often ignored or downplayed, and that is, moral character. What I have 
argued is that the virtue of temperance in particular shows us the basis for rejecting in vitro meat, even under the assumption that it delivers what it promises.

Acknowledgements I would like to thank Malaika Alvaro, Tyler Perkins, and the anonymous referee for providing insightful comments that helped improve this paper.

\section{References}

Alvaro, C. (2017a). Veganism as a virtue: How compassion and fairness show us what is virtuous about veganism. Future of Food: Journal on Food, Agriculture and Society, 5(2), 16-26.

Alvaro, C. (2017b). Ethical veganism, virtue, and greatness of the soul. Journal of Agricultural and Environmental Ethics, 30(6), 765-781.

Alvaro, C. (2019). Ethical Veganism, Virtue Ethics, and the Great Soul, Lexington Books.

Anscombe, G. E. M. (1958). Modern moral philosophy. Philosophy, 33(124), 1-19.

Aristotle. (2002). Nicomachean Ethics. In Sarah Broadie, Christopher Rowe (Eds.). Oxford University Press.

Bhat, Z., Kumar, S., \& Fayaz, H. (2014). In vitro meat production: Challenges and benefits over conventional meat production. Journal of Integrative Agriculture, 14, 241. https://doi.org/10.1016/ s2095-3119(14)60887-x.

Bouvard, V., Loomis, D., Guyton, K. Z., et al. (2015). Carcinogenicity of consumption of red and processed meat. The lancet Oncology, 16, 1599. https://doi.org/10.1016/s1470-2045(15)00444-1.

Collins, N. (2012). Test tube hamburgers to be served this year. The Telegraph, 19, 349.

Craig, W. J., \& Mangels, A. R. (2009). Position of the American Dietetic Association: Vegetarian diets. American Dietetic Association, 109(7), 1266-1282.

Current Eating Patterns in the United States. (2015). Dietary Guidelines 2015-2020. https://healt h.gov/dietaryguidelines/2015/guidelines/chapter-2/current-eating-patterns-in-the-united-state s/\#current-eating-patterns-in-the-united-states.

Gajdusek, D. C., \& Zigas, V. (1957). Degenerative disease of the central nervous system in New Guinea. The endemic occurrence of "kuru" in the native population. New England Journal of Medicine, 257, 974-978.

Hocquette, J. F. (2016). Is in vitro meat the solution for the future? Meat Science, 120, 167-176. https ://doi.org/10.1016/j.meatsci.2016.04.036.

Hursthouse, R. (1991). Virtue Theory and Abortion. Philosophy \& Public Affairs, 20(3), 223-246.

Johns Hopkins Bloomberg School of Public Health (n.d.). Health \& environmental implications of U.S. meat consumption \& production. https:/www.jhsph.edu/research/centers-and-institutes/ johns-hopkins-center-for-a-livablefuture/projects/meatless_monday/resources/meat_consumptio n.html. Accessed 3 June 2018.

Joy, M. (2001). From carnivore to carnist: liberating the language of meat. Satya., 18(2), 126-127.

Kass, L. (1997). The Wisdom of Repugnance. The New Republic, 216(22), 17.

Louden, R. (1984). On some vices of virtue ethics. American Philosophical Quarterly, 21(3), 227-236.

Nussbaum, M. (2004). Danger to human dignity: The revival of disgust and shame in the law. The Chronicle of Higher Education, 50, B6.

Phillips, A. (2009). PETA Offers \$1 M Prize for lab-grown meat. ABC News. https://abcnews.go.com/ Technology/story?id=4704447\&page=1. Accessed 2 Feb 2019.

Schaefer, G. O., \& Savulescu, J. (2014). The ethics of producing in vitro meat. Journal of Applied Philosophy, 31(2), 188-202. https://doi.org/10.1111/japp.12056.

Stripp, C., Overvad, K., Christensen, J., Thomsen, B. L., Olsen, A., Møller, S., et al. (2003). Fish intake is positively associated with breast cancer incidence rate. The Journal of Nutrition, 133(11), 3664-3669. https://doi.org/10.1093/jn/133.11.3664.

Tuso, P. J., Ismail, M. H., Ha, B. P., \& Bartolotto, C. (2013). Nutritional update for physicians: Plantbased diets. The Permanente Journal, 17(2), 61-66. https://doi.org/10.7812/TPP/12-085. 
Vegetables and Fruits. (2019). Harvard T.H. Chan. School of Public Health. The Nutrition Source. https://www.hsph.harvard.edu/nutritionsource/what-should-you-eat/vegetables-and-fruits/.

Vogel, G. (2010). Organs made to order. SMITHSONIAN MAGAZINE, August 2010. https://www.smith sonianmag.com/science-nature/organs-made-to-order-863675/.

Publisher's Note Springer Nature remains neutral with regard to jurisdictional claims in published maps and institutional affiliations. 